\title{
Schwankender Blutdruck als Risikofaktor für zerebrovaskuläre Erkrankungen
}

\begin{abstract}
Das Schlaganfallrisiko ist nicht nur bei älteren Hypertonikern erhöht. Auch Senioren mit stark schwankenden Blutdruckwerten sind stärker gefährdet.

- Für die Studie der Columbia-University New York wurden 686 nicht demente Personen über 65 Jahren rekrutiert. Bei ihnen war im Abstand von je 24 Monaten dreimal der Blutdruck gemessen worden. Mittels Magnetresonanztomografie wurde bei den Probanden nach signaldichten Strukturen in der weißen Hirnsubstanz gesucht und

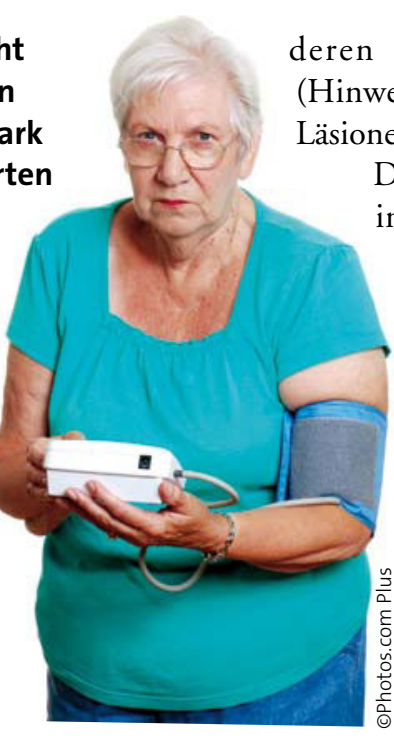

Beim Blutdruck kommt es nicht nur auf die Höhe an.

deren Volumen bestimmt (Hinweis auf zerebrovaskuläre Läsionen).

Die Probanden wurden in vier Gruppen eingeteilt: normotensiv mit geringen Blutdruckschwankungen (Gruppe I), normotensiv mit stärkeren Blutdruckschwankungen (Gruppe II), hypertensiv mit geringen Schwankungen (Gruppe III) und hypertensiv mit starken Schwankungen (Gruppe IV). Die Zahl der im Magnetresonanztomo-
\end{abstract}

gramm nachgewiesenen Läsionen und auch deren Volumen nahm von Gruppe I bis Gruppe IV stetig zu.

\section{Kommentar}

Die Studie zeigt, dass das Risiko, zerebrovaskulär zu erkranken, nicht nur von der Höhe des Blutdrucks abhängt. Starke Blutdruckschwankungen sind ein eigenständiger Risikofaktor, der sowohl in der Therapie als auch in der Prävention zerebrovaskulärer Ereignisse stärker berücksichtigt werden muss.

K. MALBERG =

\section{- A. M. Brickman et al. \\ Long-term blood pressure fluctuation and cerebrovascular disease in an elderly cohort. Arch. Neurol, 67 (2010) 564-569}

\section{Das letzte Abendmahl in Supersize}

\begin{abstract}
Die Tendenz hin zu immer größeren Essensportionen begann nicht erst im Zeitalter von McDonalds, sondern zeichnete sich auch schon durch die Jahrhunderte in der Darstellung des berühmtesten Mahls der Welt ab.
\end{abstract}

— Einer der Gründe für die endemische Zunahme der Adipositas ist sicher die weitverbreitete Verfügbarkeit von Essen, die laufende Zunahme der Portionsgrößen und die kalorische Verdichtung der Nahrungsmittel. Während es sich hierbei um ein historisch relativ junges Phänomen handelt, scheint der Trend hin zu immer größeren Portionen bereits vor Jahrhunderten begonnen zu haben.

In einem wahrscheinlich nicht ganz ernst gemeinten Ansatz haben das ein Ökonom und ein Theologe anhand der Analyse von 52 der bekanntesten Darstellungen des letzten Abendmahls aus den Jahren 1000 bis 2000 n. Chr. herausgefunden. Dabei wurden die Größe der Brotlaibe, der Hauptgerichte und der Teller unter Verwendung eines CAD-CAM-Computerprogramms in Relation gesetzt zur Größe der dargestellten Köpfe und daraus ein Index gebildet. Ein Index von 2,0 für das Brot würde bedeuten, dass die durchschnittliche Breite des Brotes das Doppelte der durchschnittlichen Breite eines Apostelkopfs beträgt. Neben dem Brot waren auf $18 \%$ der Gemälde Fisch, auf 14\% Lamm und auf 7\% Schweinefleisch dargestellt. Auf den übrigen Gemälden $(46 \%)$ fand sich kein identifizierbares Hauptgericht.

In Abhängigkeit zur Entstehungszeit des Bildes war ein signifikanter Trend der dargestellten Nahrungsmittel hin zu immer größeren Portionen feststellbar. Im Vergleich zu den um $1000 \mathrm{n}$. Chr. entstandenen Darstellungen nahm die Größe der Hauptgerichte bis zur Zeit um 1750 um 69,2\%, die Größe der Brote um 23,1\% und die Größe der Teller um 65,6\% zu. Die mathema- tische Analyse ergab ein nonlineares Regressionsmodell wegen der deutlich wachsenden Größenzunahme der Portionen im Zeitraum zwischen 1500 und 2000 n. Chr..

\section{Kommentar}

Mit diesen ersten Untersuchungen am Beispiel der Darstellungen des letzten Abendmahls haben die Wissenschaftler möglicherweise ein ganz neues Forschungsgebiet eröffnet. Die Größe der Essensportionen in Fernsehsendungen, Filmen oder auf Reklameanzeigen erlaubt tiefschürfende Erkenntnisse über unsere Esskultur und lässt vielleicht ganz neue Einsichten über die Pathogenese der Adipositas zu. H.S. FüEßL = 